\title{
Coming in to the cold
}

\section{Daniel Branton}

Low Temperature Methods in Biological Electron Microscopy. By A.W. Robards and U.B. Sleytr. Elsevier:1985. Pp.551. Hbk \$111, Dfl. 300; pbk\$48.25, Dfl. 130.

GREATER USE of low-temperature methods and frozen specimens in biological electron microscopy has resulted from recent advances in a variety of morphological and analytical applications, especially freeze-etching, immunocytochemistry and the direct examination of hydrated frozen specimens. While all of these applications depend upon the use of frozen specimens, workers experienced in one particular area will, upon reading Robards and Sleytr's book, discover welldeveloped traditions and critical manipulations that have simply not crossed the boundary between, for example, those laboratories engaged in freeze-etching and those doing cytochemistry of frozen sections. For the expert, this book is the equivalent of an informative tour of distant laboratories. Here they will learn of the latest "tricks" in freezing biological materials, direct viewing of frozen specimens, freeze-sectioning, freeze-drying, freeze-substitution, low-temperature embedding and freeze-fracturing.

The book will also be very helpful for the non-expert. It is a clear and accurate survey of a large number of methods, almost all of which are illustrated and wisely accompanied by detailed description and discussion. Although the amount of detail may appear excessive, success with lowtemperature methods often hinges on apparently minute points. Freezing and freeze-etching methods are particularly well covered, and attention is given to tissue differences and important principles of sampling and interpretation that are often overlooked in "methods" books. Throughout, the authors provide critical comparisons and sufficient background and theory so that readers can decide for themselves what they can hope to gain by using low-temperature methods, and which method should be selected from the many available.

The book is abundantly illustrated but the graphics are often disappointing. The authors' attempt to be comprehensive is admirable, but the introductory diagrams are sometimes so cluttered with details of alternative pathways that many readers will have the impression of being given an unabridged chart of intermediary metabolic pathways before even having been introduced to the tricarboxylic acid cycle. An appendix listing suppliers of commercially available equipment is included, but it is not as useful as it could have been: there are too few listings under specific categories and little attention has been given to suppliers outside Europe.

A breakthrough in low-temperature electron microscopy has been the demonstration that biological specimens can be vitrified. Although some of the techniques for the preparation and direct viewing of vitrified specimens at high resolution are included, the coverage here is neither as well organized nor as complete as this promising area deserves. To be fair, these methods are very recent; but it is regrettable that Robards and Sletyr did not have more of an opportunity to comment on these advances, for they have otherwise produced a discerning and up-to-date reference work.

Daniel Branton is Higgins Professor in the Department of Cellular and Developmental Biology, Biological Laboratories, Harvard University, 16 Divinity Avenue, Cambridge, Massachusetts 02138, USA.

\section{Graded grains}

\section{Peter D. Moore}

Numerical Methods in Quaternary Pollen Analysis. By H.J.B. Birks and A.D. Gordon. Academic:1985. Pp.317. \$59, $£ 45$

Pollen Records of Late-Quaternary North American Sediments. Edited by Vaughn M. Bryant Jr and Richard G. Holloway. American Association of Stratigraphic Palynologists Foundation, PO Box 819047 , Dallas, Texas 75381, USA:1985. Pp.426. $\$ 35$.

ONE of the most valuable features of pollen grains as palaeoecological material is their sheer abundance. Combine this with their capacity to survive well in peats and lake sediments, and we have in fossil pollen assemblages a splendid opportunity to use numerical methods for their analysis. This was immediately apparent to von Post when he first came upon pollen in peat and it has been exploited by all subsequent research workers in the area. Until the 1960 s numerical analysis was restricted to the expression of pollen counts in terms of percentage values, but since then there has been rapid growth in ways of treating data in order to improv? their value to the palaeoecologist. Amorng those who have led this field of enquiry, few have contributed more to its development than the authors of Numerical Methods in Quaternary Pollen Analysis.

In their book, Birks and Gordon present a critical review of the current state of each aspect of Quaternary palynology to which numerical techniques have been applied, commencing with the most obvious, the presentation of pollen data. The use of binomial and multinomial models, as originally described by Mosimann, is explained in some detail, though, as a basis for establishing homogeneity within a section of the stratigraphic profile, ordination methods are preferred. This involves the classification of samples, using spatial models, on the basis of dissimilarity indices.

This approach provides a number of opportunities to the palynologist, one of which is the establishment of objectively determined zones. These are subdivisions of the pollen profile into relatively homogeneous subunits for the sake of simplicity. In the early days a subjective approach to this process was considered perfectly adequate, since zones are simply aids to description of pollen proportions in time (that is, vertical space in the sediments). Recently many research workers have questioned the need for such zones at all, because they have led to a great deal of confusion in the past, while others feel that each of the main pollen taxa should be zoned independently. One wonders, therefore, whether sophisticated methods of zonation based on tests of homogeneity are necessary, but the practice is unlikely to do any harm and it may give confidence in the location of lines of maximum change.

Much more useful, in my opinion, is the application of the same group of techniques to follow the course of development of pollen assemblages through time, to compare one sequence with another and to set a fossil sequence in the context of modern pollen studies. Here the numerical approach comes into its own and many of those who doubted the value of these methods in the past, myself among them, have now become regular users.

Several variants of ordination methods are currently available for this type of work and they are well known to phytosociologists. These techniques are well explained by Birks and Gordon, and their application to palaeoecology is set out with clarity and enthusiasm. Many waverers have already been converted to their use and this book will be a means of initiating yet more palynologists into an increasingly fruitful type of analysis. Altogether, no palynological laboratory can afford to be without this compendium.

The second book under review, a manual of results rather than methods, is a long overdue synthesis of the vegetation history of North America through the late Pleistocene and Holocene. It is divided into geographical regions, ranging from Mexico to Alaska and Texas to Quebec, each dealt with by a different author. In each chapter representative pollen diagrams are reproduced and the variation in vegetation history is described, together, where appropriate, with assessments of climatic variations and human impact.

The emphasis is naturally upon vegeta- 